\title{
Towards Globalisation and the Virtual Enterprise
}

\author{
J.A. Sharp
}

A. Paterson

Canterbury Business School, University of Kent, Canterbury, CT2 7PE, UK

Tel. +44 (0)1227827787 Fax +44(0)1227 761187,

Email J.A.Sharp@ukc.ac.uk

\section{R. Beach}

\section{A.P. Muhlemann \\ D.H.R. Price \\ Management Centre \\ University of Bradford \\ Bradford \\ $U K$}

\section{Abstract}

We describe certain of the outputs of a research project on competence development in manufacturing firm. We consider the results with particular reference to globalisation, agile manufacturing and the virtual enterprise and discuss their implications for the future shape of manufacturing. Our research enables us to comment on these three issues. and this paper assesses the current importance of competences associated with them and the likely rate of progress of each of them in the next few years.

\section{Keywords}

Globalisation, Strategy, Competences, Virtual Manufacturing, Agile Manufacturing 


\section{INTRODUCTION}

Despite the fact that all three are underpinned by the same enabling information technologies, there is a marked difference in the way that the concepts of globalisation, virtual manufacturing and agile manufacturing have emerged. As long ago as the 1970s, the first came to be recognised as a clear trend in the behaviour of multinational manufacturing firms, which had expanded internationally in the 1950 s and 1960s. Pioneering firms could be found that coordinated production on an international basis. By the end of the 1970s, there was much interest, e.g. in the automobile industry, in devising products that could be sold in more than one country (Hayes et al., 1988). This was further reinforced by the opportunities afforded by growing Asia Pacific markets and the completion of the Single European Market.

Thus the growth of globalisation could be observed through changes in the way in which manufacturing organisations operated from the 1970s on. Virtual manufacturing took much longer to emerge as a concept and has only recently begun to be reflected in manufacturing organisations. The concept has its roots in the Transaction Cost Economics ideas of Williamson (1975) which advocated that manufacturing firms should make a much greater use of externally purchased goods and services rather than internally supplied ones. The biggest impact of these ideas was in the growth of outsourcing during the 1980s (Lacity and Hirschheim, 1993). Related ideas from an organisational perspective can be found in Handy's (1984) recognition of the 'Shamrock Organisation' and Snow et al's (1992) ideas of network organisations. The reality was, however, that computer technology up until the early 1990's favoured rather rigid links, e.g. EDI agreements, between manufacturing organisations. They did not support the notion of constant reconfiguration of networks of manufacturing organisations mediated by information technology. Thus as late as 1990, Huber writing on the impact of IT on organisational design makes no mention of the possibility of virtual organisations. It is only with the growth in importance of the Internet and subsequent developments such as Java and Intranets that the idea of virtual manufacturing has begun to be translated into reality.

The concept of agile manufacturing on the other hand, might be viewed as intermediate between the previous two. It represents a logical development of ideas inherent in JIT and notions of time based competition (Keen, 1986, Blackburn, 1991).

In reality, however, the extent to which the ideas of agile manufacturing and virtual manufacturing are implemented depends on exactly the same real world processes that led to globalisation. Investments in processes and hardware have to be made and services need to be developed by service providers. Even more importantly, manufacturing firms must develop competences or capabilities (Teece et al., 1997) that support these new forms of manufacturing organisation.

The authors have been engaged, during the past 3 years, in a project in a large 
number of UK manufacturing firms that is concerned with the way that the competences that exist within those firms, and the competences that they are actively seeking to develop, impact on the strategies being pursued by these firms..

The project has developed a decision support tool that aims to measure and to extend the potential of manufacturing firms to support evolutionary strategic change.

This paper is particularly concerned with the competences required to operate certain global strategies and with some of the implications of the relationships between competences and strategies that were established in the research.

\section{COMPETENCES AND STRATEGIES}

Our notion of Competence is a combination of resources and abilities which provide competitive advantage to manufacturing firms. As indicated above, our view of the relationship between competences and strategies is that a set of competences are required to pursue any particular strategy and different strategies will require (somewhat) different sets of competences, if they are to be pursued successfully. As we shall see later, some strategies require more competences to be pursued successfully than do other, simpler strategies.

The idea of Competence with which we are operating is then a more modest one than the Core Competence of Prahalad and Hamel (1990). For us competences are sets of abilities and resources that are common to all the manufacturing firms that are successfully pursuing a particular strategy, though we do not assume that all such firms have necessarily developed all the competences to the same extent. Essentially, this is the same notion as that of a Capability (Teece et al., 1997).

\subsection{Identification of the Competences}

The competences that are important to UK manufacturing firms were identified using a NUD*IST analysis (Gahan and Hannibal, 1997) of 32 case studies in UK manufacturing firms that were selected in accordance with our overall research design (Sharp et al., 1998a). The breakdown by broad business area of the 171 competences identified is shown by the unbracketed figures in Table 1 .

Table 1 - Breakdown of Competences Identified from the Case Studies

\begin{tabular}{lrlr}
\hline Manufacturing & $20(6)$ & Procurement & $9(3)$ \\
Marketing & $26(6)$ & Product & $17(4)$ \\
Human Resource Management & $21(4)$ & Strategy & $7(1)$ \\
Financial/Accounting & $10(1)$ & Organisational & $25(6)$ \\
IT & $36(5)$ & Total & $\mathbf{1 7 1 ( 3 6 )}$
\end{tabular}


Table 2

The 11 global generic

strategies identified

\section{Global Generic Strategy \\ Description}

Cost

Compete with other companies by having low cost products compared with theirs

Exploitation of Product Application Compete by having product/ application Knowledge knowledge that is superior to that of competitors.

Response to Customer Requirements

Place great emphasis on responding to changing customer priorities

Customer Support

Compete by advice on correct application of products and/or providing exceptional after sales service

Use of Third Party Technology

Employing technology from third parties to increase the functionality of the product or product range.

New Product Introduction

Emphasis on frequent new product introductions and high proportion of products introduced in past few years

Product Functionality/Performance

Compete on the basis of offering superior product performance or functionality

Product Range

Compete on the basis of offering a complete range of products for every purpose.

Product Quality/Reliability

Compete on the basis of offering customers superior product quality or reliability

Concentration on Marketing Core Compete by having identified your Competences firm's core competences and marketing them aggressively

Concentration on Industry Leadership Emphasis on gaining and maintaining a reputation as a leading firm in industry or a World Class Manufacturer. 


\subsection{Identification Of The Strategies}

The strategies used in the research were identified through a NUD*IST analysis of our case study data. They represented a further breakdown of a a generic strategy classification suggested by Chrisman, Hofer and Boulton (1988) but are specific to manufacturing firms. Although broadly compatible with the research of Miller and Roth (1992), our strategies represent a distinctively UK set of approaches to manufacturing strategy.

Three distinct groups of strategies were identified: UK Based Strategies (i.e. firms who were essentially focused on the UK) and Global Strategies (i.e. firms whose focus was essentially global) and a third group who were located between the other two. In a national survey carried out as part of our research we found the percentages in the 3 groups to be: UK Based 21\%; Global Based 43\%; Mixed $36 \%$.

There were 11 generic strategies identified with UK Based Strategies and 11 for Global Strategies. The 11 Global Strategies were identical to the UK Based strategies in all respects except the scope of the firm's operation. Since they will be the focus of subsequent discussion, the 11 Global Strategies are listed in Table 2.

\section{MODEL UNDERLYING THE DECISION SUPPORT TOOL}

The core model of the decision support tool is that the extent to which a particular competence is possessed is measured on a scale $0-100$ (maximum) and the fit $F_{i}$ of the actual competences possessed by the firm to the ith Strategy is given by:

$F_{i}=E R_{i j} C j$

Where $C_{j}$ represents the jth Competence Score and $R_{i j}$ is the matrix of Strategy/ Competence Weights. The "Competence Gap" for the ith Strategy is then given by:

$G_{i}=E R_{i j}\left(100-C_{j}\right)$

Thus only strategies for which all needed competences, as represented by non zero values in the appropriate row of the Strategy/Competence Matrix, are fully present have a zero gap. In all other cases, the gap will be non-zero. By examining the major sources of the 'gap' it is possible to identify desirable competence developments 


\subsection{Estimation Of The Strategy/Competence Weights Matrix (R)}

A key element of the construction of the decision support tool was the estimation of the Strategy/Competence Weights Matrix (R). This matrix gives a measure of the contribution that a particular Competence makes to the achievement of a particular generic strategy. The construction of this matrix is described elsewhere (Sharp et al., 1998b).

\section{KEY COMPETENCES FOR GLOBAL GENERIC STRATEGIES}

In this section we consider the key competences identified by our research. For reasons of space and because of the focus of the paper, we confine ourselves to consideration of the global strategies. However, the results are broadly similar for the corresponding UK Based strategies.

It is of interest to examine which are the most important Competences. The measure of Key Competences adopted here is those Competences, that, on average, contribute most to the strategies. Those 32 Competences with mean weights across the Global Generic Strategies of more than 30 are displayed in Table 3 which is sorted in descending order of the average score listed. For reasons of space, the phrase Ability to... has been omitted from most of the competences listed.

As can be seen from Table 3, the highest mean weight across the 11 global generic strategies was Flexible Manufacturing Response, which was the only Competence with a mean weight in excess of 100 . Only two other Competences have weights above 60. Over half (17) have mean weights between 31 and 40 .

\subsection{The Mix of Key Competences For Global Generic Strategies}

The third column of Table 3 shows the Table 1 group of competences to which the Competence listed in the first column belongs. It will be noted that four of the competences have actually been associated with two groups: one with both Manufacturing and IT, and three with both Marketing and Product . This gives 36 identifications in all. The number of Top 32 Competences associated with each of the groups is shown by the bracketed figures in Table 1 .

Although the identification of the full list of 171 competences with particular business areas involved a few ambiguities, e.g some overlap between Human Resource Management, Strategy and, Organisation competences, the identifications of the Top 32 competences (given the assignment of 4 of them to two different groups) are clear and worthy of further examination. We comment on each of the groups of competences separately. In our discussion, we make use of the fourth column of Table 3, in which A, G, and V denote, respectively competences that our, and other, research shows to be particularly important in the support of Agile Manufacturing, Globalisation, and, Virtual Manufacturing. 


\section{Manufacturing}

This was not the largest group of competences identified in our research. The fact that $30 \%$ of the 20 Manufacturing competences identified appeared in the 'Top 32' suggests, however, that these were the most important single group as far as our respondents are concerned. This is, perhaps, not very surprising; most of our case study respondents had a manufacturing background. It also confirms an impression gained in our case study interviews that the reason that a relatively small proportion of the 171 competences identified were manufacturing ones was because many were

Table 3 Top 32 Global Strategy Competences Sorted By Mean Weight

\begin{tabular}{llcc}
\hline Competence & Mean Weight & Type Enables \\
\hline Flexible manufacturing response & 126 & MANF & A \\
Run effective TQM System & 83 & MANF & \\
Develop employees & 62 & HRM & G \\
Manage formal/informal procedures & 54 & HRM & G \\
Assess/plan human resources & 51 & HRM & G \\
Use new technology effectively & 51 & MANF/IT & \\
Involve suppliers & 48 & PROC & \\
Internet capability & 47 & IT & AGV \\
Develop close customer relations & 47 & MKT & G \\
Produce corporate plans & 46 & STRAT & G \\
Design capability & 46 & PROD & \\
Get design services from wide range suppliers & 46 & PROC & GV \\
Manage change & 43 & ORG & \\
Measure performance & 43 & ORG & GV \\
Acquire needed human competences & 42 & HRM & G \\
Develop new products & 40 & PROD/MKT & \\
Reduce manufacturing costs continuously & 39 & MANF & \\
Integrated accounting system & 39 & FIN & G \\
Sell output & 38 & MKT & \\
Form strategic alliances with suppliers & 37 & PROC & \\
Provide customer service & 37 & MKT & G \\
Email capability & 36 & IT & AGV \\
Ability to manufacture to high quality & 36 & MANF & \\
Know core competences & 35 & ORG & GV
\end{tabular}


Develop existing products

Link direct to customers

Link computer systems across sites

Identify critical success factors

Focus on core business

Use CADCAM

Meet regulatory requirements of market

Change company culture
34

34

33

33

31

31

31

31
PROD/MKT

IT

G

IT

G

ORG

$\begin{array}{cc}\text { ORG } & \text { GV } \\ \text { MANF } & \text { A } \\ \text { PROD/MKT } & \end{array}$

ORG

just accepted by our respondents as indispensable to the running of an efficient manufacturing operation and were therefore deemed unworthy of mention. Our case studies suggest that only two Manufacturing competences are particularly associated with Agile Manufacturing, Globalisation, or Virtual Manufacturing. However, the most important competence in the list is Flexible Manufacturing Response, the pursuit of which is, clearly, a powerful driver of Agile Manufacturing. The other, Use CADCAM is a very powerful facilitator of Agile Manufacturing (Beach et al, 1998)

\section{Marketing}

Marketing competences comprise the second largest subgroup (26) in the full list of competences. Nearly $25 \%$ (6) of this group appear in the 'Top 32'. Of these six competences. 2 are clearly associated with Customer Service, while 3 which we have also associate with the Product subgroup are about the development of new or existing products. This leaves the somewhat surprising Sell Product, which appeared unexpectedly often in our case study interviews. One reason for this may be the relatively volatile exchange rate of the $£$, which means that for the globally oriented UK company, the ability to sell in foreign markets is a constant preoccupation.

The two Marketing competences associated with Customer Service are, clearly, of great importance to the global firm. So too, is that of Meeting the regulatory requirements of the market. As Gabel (1991) shows, the ability to set/meet international standards is key to competitive success in many markets.

\section{Human Resource Management Competences}

Only 4 of the 21 Human Resource Management competences that appear in the full list, are listed in the 'Top 32'. However, the first three of them appear as numbers 3,4 and 5 in the 'Top 32' ahead of any of the other non-Manufacturing competences. Three of them relate to the acquisition and development of human resources. The fourth is concerned with the management of procedures at a time when the balance between informal and formal procedures and between different levels of personnel is changing markedly.

As the research of Hofstede (1980) and Tayeb (1996) has shown, the impact of all four on the ability to follow Global Strategies is very considerable. 


\section{Financial/Accounting Competences}

Only one Financial/Accounting competence appears in the 'Top 32', Integrated Accounting System. Our case studies show that this competence is particularly important to companies pursuing Global Strategies in enabling them to account for diverse operations in many different countries in accordance with the requirements of bodies ranging from stock exchanges to tax authorities.

\section{IT Competences}

With 36 associated competences, this was the largest group in the Full List. This probably reflects the fact that the process by which that list was derived tended to identify more competences in business areas that were somewhat problematic for a lot of organisations, even if the precise problem areas differed from one company to another. We found from our case studies that IT was just such an area because of transitions from proprietary, mainframe based computing paradigms to Internet oriented PC based ones. This transition is reflected in the IT competences appearing in the 'Top 32'. Two of them, Link direct to customers, Link computer systems across sites, reflect the older, mainframe paradigm and are relatively low down the list. These two competences have long been very important facilitators of Global Strategies, as witness the evolution of IT support in firms such as Ford or Xerox. Two IT competences, Internet capability, Email capability reflect the newly emerging E-Commerce paradigm. These two competences are qualitatively different, in that they facilitate both Agile Manufacturing and, Virtual Manufacturing as well as Globalisation. It should be noted, however, that because they support a democratic, flexible set of links, they imply a new order for global computing.

The final IT competence, Use technology effectively, which appears highest in the list was actually identified originally as a Manufacturing competence. However, our case study results show that because of the importance of IT as an enabler, most new manufacturing technologies have a substantial IT component. Hence this competence has been jointly assigned to Manufacturing and IT here.

\section{Procurement Competences}

Only 9 Procurement competences appear in the Full List. Just as with Manufacturing competences, our interviews suggested that manufacturing managers tend to take them for granted. Their importance, in practice, is reflected in the fact that 3 of these 9 appear in the 'Top 32'. One of them, Involve suppliers, reflects a general trend towards Supplier reduction programmes (cf. Mannion, 1995). Both of the other two competences, Form strategic alliances with suppliers, and Get design services from a wide range of suppliers, are important supports to Global Strategies based on ideas such as World Class Manufacturing or global reputation. The latter is, furthermore, a considerable support to the development of the virtual manufacturing enterprise that can draw on the best of 
design services from anywhere in the world.

\section{Product Competences}

Three of the Product competences, Develop new products, Develop existing products, and Meet regulatory requirements of market are associated with Market competences. All of them, either directly or indirectly, support the product introduction process. The fourth Product competence, Design capability, is of a more general nature. Only one Product competence, Meet regulatory requirements of market, was found to be particularly associated with Globalisation. None were found to be particularly associated with either Agile Manufacturing or Virtual Manufacturing.

\section{Strategy Competences}

Only 7 Strategy Competences appear in the full list and only one, Produce corporate plans, appears in the 'Top 32'. This, however, appears quite high in the list reflecting the fact that a primary motivation for many of the firms that participated in our research was an interest in its potential to improve their strategic planning.

\section{Organisational Competences}

The Full List contains 25 Organisational Competences. Six of these appear in the 'Top 32'. Interestingly, on the whole, they come rather lower in the 'Top 32' than the Human Resource Competences. Two of them, Manage change and Change company culture are associated with the area of Change Management. Three of them, Know core competences, Identify critical success factors, and, Focus on core business, are concerned with an important theme identified in many our case studies and, indeed, identified as a generic strategy of, as Peters and Waterman (1982) put it, 'sticking to the knitting'. Two of them are important facilitators of moves towards both Globalisation and Virtual Manufacturing, in which activities in which the firm is not a leader are outsourced. One other Organisational competence, Measure performance was of a more fundamental nature; most organisational initiatives would founder were the organisation not in position to 'keep score'.

\section{CONCLUSIONS}

Examination of the key competences required to support Global Strategies bears out the point made in the Introduction. More of the competences are concerned with Globalisation than with either Agile Manufacturing or Virtual Manufacturing. Moreover, our case studies and our national survey showed Global Generic Strategies to be important to a high percentage of firms, as would be expected for a well established concept.

Competences associated with Virtual Manufacturing receive slightly more mentions than those associated with Agile Manufacturing. On the other hand, by 
far the most important competence in the 'Top 32', Flexible manufacturing response, is one that supports Agile Manufacturing. Furthermore, several of the competences associated with virtual manufacturing represent new Internet-related technologies.

With regard to Agile Manufacturing and Virtual Manufacturing, then, Table 3 is broadly consistent with the thesis that Agile Manufacturing has evolved over quite a long period, whilst many of the key competences that underpin Virtual Manufacturing are of very recent origin. A reasonable deduction would seem to be that the next few years will see a further increase in the attractiveness of Virtual Manufacturing ideas.

\section{REFERENCES}

Beach R., Muhlemann, A.P. Price, D.H.R. Paterson, A. and Sharp, J.A. (1998) Information systems as a key faciliator of manufacturing flexibility: a documented application, Production Planning and Control, 9, 96-105

Blackburn, J.D. (1991) Time-Based Competition: The Next Battleground in American Manufacturing, Business One-Irwin, Homewood ILL

Chrisman, J.J., Hofer C.W. and Boulton, W.R. (1988) Toward a System for Classifying Business Strategies, Academy of Management Review, 13 , 413-28

Gabel, H.L. (1991) Competitive Strategies for Product Standards, McGraw Hill, London

Gahan, C. and Hannibal, M. (1997) Doing Qualitative Research Using QSR NUD.IST, Sage Publications, London

Handy, C.B. (1984) The Future of Work: a guide to a changing society, Blackweill, Oxford

Hofstede, G.H. (1980) Culture's consequences: international differences in workrelated values, Sage, London

Huber, G.P. (1990) A Theory of the Effects of Advanced Information Technologies on Organizational Design, Intelligence, and Decision Making, Academy of Management Review, 15, 47-71

Keen (1986) Competing in Time: Using Telecommunications for Competitive Advantage, Ballinger Publishing Company, Cambridge MA

Lacity, M. and Hirschheim, R. (1993) Information Systems Outsourcing, Wiley, Chichester

Mannion, D. (1995) Vendor Accreditation at ICL: Competitive versus Collaborative Procurement Strategies, in R. Lamming and A. Cox (eds.), Strategic Procurement Management in the 1990s, Earlsgate, Winteringham

Miller, J.G. and Roth, A,V. (1994) A Taxonomy of Manufacturing Strategies, Management Science, 40, 285-304

Peters, T. and Waterman, R. (1982) In Search of Excellence: Lessons from America's Best-Run Companies. Harper \& Row, New York 
Prahalad, C.K. and Hamel, G. (1990), 'The Core Competence of the Corporation', Harvard Business Review, 68(3), 79-91

Sharp, J.A., Price, D.H.R., Muhlemann,A.P., Beach, R., Paterson, A. (1998a) A System to Support the Enhancement of the Strategic Flexibility in Manufacturing Enterprises, European Journal of Operational Research, to appear

Sharp ,J.A., Paterson, A, Beach, R., Muhlemann, A.P., Price, D.H.R. (1998b) Computer assistance to strategies, Proceedings IFIP WG5.7 Conference Strategic Management of the Manufacturing Value Chain, Troon, Scotland

Snow, C.C., Miles, R.E., Coleman, H.J. (1992) Managing $21^{\text {st }}$ Century Network Organizations, Organization Dynamics, 20(3) 5-9

Tayeb, M.H. (1996)The management of a multicultural workforce, John Wiley \& Sons, Chichester

Teece, D.J., Pisano, G. and Shuen, A. (1997) Dynamic Capabilities and Strategic Management, Strategic Management Journal, 18, 509-533

Williamson, O.E. (1975) Markets and Hierarchies, Free Press, New York

\section{BIOGRAPHY}

Roger Beach is Lecturer in Operations Management at the University of Bradford Management Centre. His research interests include: computer aided production management, operations strategy and contemporary information system models.

Alan Muhlemann is Professor of Operations Management at the University of Bradford Management Centre. His research interests include: operations planning and control, operations strategy and service sector applications.

Andrew Paterson has worked widely in manufacturing industry. His research interests include: business strategy and environment and management.

David Price is Reader in Manufacturing Management at the University of Bradford Management Centre. His research interests include: manufacturing management information systems, production planning and control and manufacturing strategy.

John Sharp is Professor of Management at the Canterbury Business School, University of Kent. His research interests include: manufacturing information systems design, information systems strategy and management research methods. 


\section{ACKOWLEDGEMENT}

The authors gratefully acknowledge the support of the Engineering and Physical Sciences Research Council (EPSRC) of the research on which this paper is based. 